\title{
Comissão de Ética Setorial: os desafios de fazer cumprir a ética na administração pública federal
}

Annita Valléria Calmon Mendes, Hermes de Andrade Júnior, Rodolfo Pinto da Luz e Cândido Borges

\section{Introdução}

Uma crise ética do mundo contemporâneo pode ser descrita como a discrepância entre excesso de poder e escassez de orientação para utilização desse poder (BAUMAN, 1997). Tal crise apresenta dimensões práticas que se referem à magnitude dos poderes individuais e coletivos com resultados imprevisíveis, e à multiplicidade de relações impostas por um cotidiano impessoal e com "responsabilidades flutuantes". A liberdade de escolha conduz a um estado de incerteza que, para o autor, refletirá em ambiguidade moral. A ética, considerada como código moral, julga os ideais humanos como um desafio, e a ambivalência dos juízos morais como um desequilíbrio a ser corrigido. A crise moral reverbera, assim, em crise ética. Bauman acredita que o código de ética universal nunca será encontrado, pois a moralidade não ambivalente e a ética universal com parâmetros objetivos constituem-se impossibilidade prática ou contradição nos termos. 
As considerações de Bauman (1997) podem ajudar a entender o Brasil dos anos 1990, quando os processos de redemocratização e reestruturação do Estado estão em curso. Ao mesmo tempo, vivenciam-se transformações sociais e econômicas em âmbito interno e internacional, e a crise da ética pública explicita-se. A preocupação em nível político sobre a questão da ética desencadeia uma série de ações que passam a constituir uma política pública de gestão da ética. Segundo Amorim (2000), esse processo se inicia em 22 de junho de 1994 com o Decreto $\mathrm{n}^{-}$1.171, que aprova o Código de Ética Profissional do Servidor Público Civil do Poder Executivo Federal. Em 1999, é criada a Comissão de Ética Pública; em 2000, é aprovado o Código de Conduta da Alta Administração Federal. O Sistema de Gestão da Ética do Poder Executivo Federal foi instituído em 2007, e compõe-se pela Comissão de Ética Pública da Presidência da República (CEP/PR), coordenadora do Sistema, e pelas Comissões de Ética Setoriais de cada órgão do Poder Executivo Federal.

A Presidência da República mantém o portal da Comissão de Ética Pública, onde estão disponibilizadas informações sobre cursos, legislação, histórico, publicações e atividades da Comissão. No entanto, apesar de o Decreto estabelecer a constituição de um Sistema de Gestão da Ética, não há, no portal, menção sobre as características dele. Há um programa constituído para a gestão da ética? Quantos são os membros do Sistema? Qual a sua abrangência? As respostas às perguntas não estão explícitas e para o mapeamento é necessário buscar em outros portais do governo federal como, por exemplo, do Instituto de Pesquisa Econômica Aplicada (IPEA) e Ministério do Planejamento, Orçamento e Gestão (MP).
Além das normas específicas para a condução da gerência da ética, o governo federal criou o portal Transparência Pública e ampliou as ações da Corregedoria-Geral da União. O conjunto de ações pode ser entendido como resposta aos anseios da sociedade brasileira e da comunidade internacional por uma administração pública orientada por valores éticos.

O estudo de dois casos - um de sucesso e outro de fracasso na implementação das Comissões de Ética Setoriais pretende identificar lacunas no processo adotado para implantação dessas Comissões e, a partir disso, sugerir ações que favoreçam a efetiva implementação delas e os meios para transpor as dificuldades inerentes ao processo. Houaiss (2004) define a palavra implementação como pôr em execução, pôr em prática um plano, projeto ou programa. Considera-se, portanto, implementação como processo para executar as atribuições das Comissões de Ética Setoriais como previsto no capítulo II do Código de Ética Profissional do Servidor Público Civil do Poder Executivo Federal (orientar e aconselhar sobre a ética profissional do servidor) bem como no Decreto $n^{\circ}$ 6029/2007, que institui o Sistema de Gestão da Ética do Poder Executivo Federal: atuar como instância consultiva, desenvolver ações de disseminação e capacitação sobre as normas de ética; apurar denúncias.

O Sistema de Gestão da Ética do Poder Executivo Federal tem o objetivo de promover atividades que dispõem sobre a conduta ética no Poder Executivo Federal por meio de apoio ao desenvolvimento de políticas públicas e à instituição de Comissões de Ética Setoriais nos órgãos da administração pública federal. A instituição das Comissões de Ética Setoriais, bem como a efetiva atuação delas, reflete a preocupação 
do governo federal em implantar um sistema integrado de gestão da ética com o objetivo pedagógico de prevenir condutas incompatíveis com o padrão ético desejável para o desempenho de funções públicas. O entendimento é que a prevenção se dá por meio do conhecimento de parâmetros esperados, adquiridos por atividades educacionais contínuas (BRASIL, 2007).

A regulação da conduta ética dos agentes públicos federais versa sobre os temas: atendimento a usuários, brindes, presentes e viagens, conduta pessoal, conflitos de interesses, controle, desempenho, exercício de atribuições, favorecimento, hierarquia, local de trabalho, outra atividade, participação em eventos, patrimônio pessoal, prejuízo ao erário, prestação de contas, publicidade e tráfico de influências. Os órgãos competentes para supervisionar o cumprimento das matérias reguladas são: Comissões de Ética Setoriais; administração e corregedoria do órgão ou entidade; Advocacia-Geral da União (AGU); Casa Civil; Secretaria Executiva da Comissão de Ética Pública; Comissão de Licitação do órgão ou entidade; Corregedoria-Geral da União (CGU); Ministério Público Federal (MPF); Secretaria Federal de Controle (SFC) e Tribunal de Contas da União (TCU).

A implementação das Comissões de Ética Setoriais consiste, assim, em componente fundamental no Sistema de Gestão da Ética do Poder Executivo. No entanto, para Matias-Pereira (2008), concretizar a promoção da ética não é tarefa simples. $\mathrm{Na}$ mesma direção, DaMatta (2001) considera que a ética como instrumento de gestão focaliza a complexa dialética entre o princípio da compaixão e da justiça e explicita de forma abrupta o dilema colocado com cinismo realista pelo moto "Aos inimigos a lei; aos amigos, tudo". Por isso suscita as mais diversas reações contrárias à sua implementação, sobretudo à execução prática.

Para Frey (2000), o processo de colocar em prática as Comissões de Ética Setoriais é tão complexo quanto os valores e condutas que objetiva instituir porque envolve atores com interesses individuais e coletivos: a administração pública, os servidores públicos e a sociedade civil, os quais agem segundo os interesses pessoais

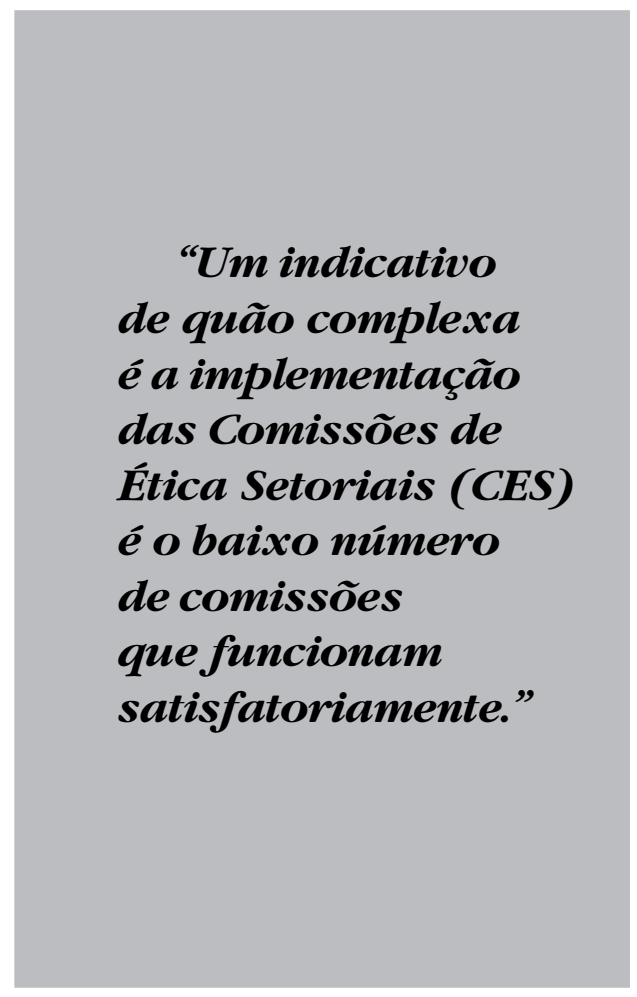

e as identidades sociais. O modelo top-down, utilizado pelos gestores públicos para a implementação da política pública de gestão da ética, identifica os policy makers como controladores do processo de formulação da política. No entanto, o hiato entre as aspirações desses atores e as realidades locais causa dificuldades no processo de implantação (OEI, 2002). Chanlat (1992) 
observa, assim, que além das dificuldades inerentes ao modelo de implementação adotado, valores definidos por regras que norteiam a conduta individual conduzem as relações sociais em organizações e, dado à característica individualista das sociedades ocidentais, a lógica individual prevalece sobre a coletiva, o que gera obstáculos ao desenvolvimento de relações de reciprocidade, as quais norteiam a ética e os códigos deontológicos profissionais.

Depreende-se dessa consideração que há uma visão de mundo exclusivista e oportunista presente no serviço público, aqui estudado como organização. A lógica coletivista apontada está imersa na necessidade de resultados ajustados por parte de um conjunto de profissionais bem preparados tecnicamente, mas socializados num contexto de mudança que sugira o coletivo para além do normativo em suas realidades cotidianas e escolhas pessoais. A extrema vantagem disso só pode ser para aquilo que mais se questiona: a seriedade e o gargalo de recursos comprometidos.

Um indicativo de quão complexa é a implementação das Comissões de Ética Setoriais (CES) é o baixo número de comissões que funcionam satisfatoriamente. Segundo dados da Secretaria Executiva da Comissão de Ética Pública da Presidência da República em resposta a uma consulta por e-mail (2008), dos 307 órgãos do Poder Executivo Federal, 221 constituíram as próprias Comissões de Ética. Em termos percentuais, após 15 anos de vigência do Código de Conduta Ética Profissional do Servidor Público com a determinação de que cada órgão da Administração Pública Federal constituísse a própria Comissão de Ética e elaborasse Código de Ética específico, 28\% dos órgãos não implementaram as Comissões e dos $72 \%$ que o fizeram, muitos ainda não possuem Código de Ética próprio. As CES funcionam precariamente, conforme verificado em workshop do Curso de Gestão da Ética, promovido em junho de 2008 pela CEP / PR. Esses dados levam a crer que há dificuldades no processo de implantação de tais Comissões.

No Brasil, coexiste uma multiplicidade de órgãos com responsabilidades por zelar pela gestão da ética em diferentes níveis e esferas de governo. No entanto, é perceptível que é bastante elevado o nível de ineficiência, ineficácia e ausência de efetividade do modelo utilizado, que se apresenta complexo, incongruente e desordenado (Matias-Pereira, 2008). A dificuldade em colocar em execução as Comissões de Ética Setoriais suscita a pergunta: como implementá-las? A questão proposta reflete a necessidade de analisar os mecanismos utilizados para a implantação das Comissões de Ética Setoriais, bem como de identificar as dificuldades inerentes ao processo. É importante salientar que a ênfase na eficácia do comportamento do servidor no Código de Ética não pode aqui ser entendida como definitiva, tampouco a força legislativa do processo. De forma preliminar, o cumprimento do código precisa ser testado, conhecido, e as vertentes explicadas. Imagina-se que outros procedimentos metodológicos não normativos devam ser conhecidos a partir do aprofundamento desse estudo.

\section{Revisão da Literatura}

Daft (2006) considera como ferramentas eficazes para a configuração dos valores éticos em organizações: a liderança baseada em valores, a estrutura organizacional e os sistemas da organização. Para o autor, as lideranças dos níveis hierárquicos superiores são responsáveis pela criação e 
manutenção de uma cultura que enfatize cotidianamente a importância da conduta ética para todos os funcionários. Os Comitês de Ética, constituídos por um grupo de executivos com a atribuição de supervisionar a ética, e o Ombudsman da Ética - cargo exercido por um gerente com a função de ouvir e analisar as reclamações sobre ética - são formas para atribuir responsabilidades por valores éticos na estrutura da organização. O autor acredita que a promoção do comportamento ético em ambiente laboral depende da inserção da ética na cultura da organização. Por isso, os valores éticos devem ser incorporados às políticas e regras, o Código de Ética divulgado, os incentivos vinculados ao comportamento ético e a ética deve ser considerada no processo de seleção e treinamento de funcionários.

Os Códigos de Ética surgem nas organizações com o objetivo de disciplinar a conduta do empregado e constituir instrumento de punição rápida às transgressões de conduta. Nos anos 1990, os empregados são estimulados a levantar questões sobre condutas inadequadas dos profissionais das organizações e o Código de Ética mantém o objetivo inicial, mas incorpora a necessidade de vinculação à cultura organizacional. O código tem o objetivo de estabelecer os parâmetros da organização sobre a conduta ética dos membros e evidencia a expectativa da empresa de reconhecimento, por parte dos funcionários, das dimensões éticas do comportamento organizacional (Arruda, 1993; DAFT, 2006).

O Código de Ética deveria ser um instrumento formal que delineia a cultura, a política e os valores organizacionais, e orienta o comportamento corporativo. Para a execução de um programa de ética, o código parece ser ferramenta fundamental, pois comunica aos stakeholders as práticas e os valores éticos da instituição. O código expressa os princípios da organização e as expectativas dela sobre a conduta dos funcionários e a qualidade das relações estabelecidas entre eles. A eficiência do código depende do comprometimento dos dirigentes com os valores nele expressos e da participação de todos os empregados no processo de elaboração. Essa condição torna-se primária para a disseminação da cultura ética e a credibilidade do programa de gestão da ética (Queiroz, Dias E Prado, 2008; Sarmento, Freitas e Vieira, 2008).

Os Comitês de Ética das organizações têm a finalidade de revisar e adaptar o Código de Ética, bem como de investigar e propor soluções para os casos de transgressões éticas. Após a adoção do Código de Ética é importante que a instituição crie um comitê composto, em geral, por número ímpar de integrantes, provenientes de diferentes departamentos e reconhecidos pelos colegas de trabalho por terem ilibada conduta. Além do comitê, há organizações que nomeiam um profissional da ética, vinculado à direção e com autonomia plena, para coordenar os programas $\mathrm{da}$ área. Esse profissional tem como atribuições manter atualizado o Código de Ética, segundo as necessidades dos stakeholders; promover treinamento dos empregados com o objetivo de disseminar a cultura ética na organização e implementar um sistema de monitoramento do programa (QueIroz, Dias E PRAdo, 2008). Em administração contemporânea aprende-se que os servidores públicos são alcançáveis pelo conceito. Isso ocorre porque eles são alvos e não apenas executores das medidas propostas pela organização pública; são usuários e também necessitam de alguns dos serviços que acabam por prestar como servidores no cotidiano de trabalho. 
As Comissões de Ética Setoriais dos órgãos e entidades da administração pública federal direta, indireta autárquica e fundacional, ou em qualquer órgão ou entidade que exerça atribuições delegadas pelo poder público, têm o objetivo de orientar e aconselhar sobre a ética profissional do servidor no tratamento com as pessoas e com o patrimônio público, competindo-lhes conhecer concretamente de imputação ou de conduta suscetível de censura (Brasil, 2007). Compete-lhes, também, no âmbito dos respectivos órgãos e entidades, funcionar como projeção da $\mathrm{CEP} / \mathrm{PR}$, supervisionar a observância do Código de Conduta da Alta Administração Federal e, quando for o caso, comunicar a essa Comissão a ocorrência de fatos que possam configurar descumprimento do mencionado Código, bem como promover a adoção de normas de conduta ética específicas para os servidores dos órgãos a que pertençam (BRASIL, 2007).

O Decreto de 18 de maio de 2001 dá providências sobre o relacionamento das Comissões de Ética de órgãos e entidades da administração federal com a Comissão de Ética Pública. Nesse decreto, as comissões de ética dos órgãos e entidades passam a ser chamadas de Comissões de Ética Setoriais. O estudo adota, portanto, essa nomenclatura para designar as Comissões de Ética que integram o Sistema. Em 2007, com a instituição do Sistema de Gestão da Ética do Poder Executivo Federal, à CEP atribuem-se as competências para atuar como coordenadora, avaliadora e supervisora do Sistema.

As Comissões de Ética Setoriais acumulam funções normativas, de divulgação, de investigação e de sanções, e apresentam paradigmas similares aos das comissões de ética empresariais, que constituem elementos estruturais para implantar políticas relacionadas com a ética no âmbito organizacional. Nas organizações, a estratégia de implementar essas comissões denota que as empresas reconhecem que os empregados podem enfrentar dilemas morais e sugerem que a direção apóie os esforços no sentido de tomar as decisões certas (WILEY, 1997). A ética também constitui elemento essencial para o desenvolvimento econômico e deve ser entendida como uma prática social que influencia os planos estratégicos de empresas e governos pressupondo a adoção de princípios de governança, os quais mensuram a capacidade para a gestão de condutas antiéticas e se consubstanciam em eqüidade, transparência, ética, prestação de contas (Lameira, 2008; Clegg, Carter e Kornberger, 2004; Machado Filho e ZyLbersZTAjn, 2004).

Estabelecer alto padrão de conduta no serviço público tornou-se tema crítico para os países membros da OCDE. Reformas administrativas que envolvam esforços de responsabilidade e discrição dos servidores públicos, pressões orçamentárias e novas formas de oferecer os serviços públicos constituem desafios aos valores tradicionais da esfera pública. Assim, o processo de prevenção de transgressões éticas é tão complexo quanto o fenômeno de transgressão em si. Por isso uma rede integrada de mecanismos é necessária para o sucesso da implementação de um sistema de gestão da ética (OCDE, 1998).

Carneiro (1998) afirma que o arcabouço jurídico por si não é suficiente para fazer o trabalho de orientação para uma conduta ética compatível com o serviço público. O autor entende que os órgãos coordenadores de questões éticas são instituídos para desempenhar as funções de aconselhamento, fiscalização e promoção da ética. No entanto, a 
implementação desses órgãos, comitês ou comissões requer que o tema seja inserido como prioridade no plano de ação da alta administração, além de demandar investimentos econômicos exclusivos para a implantação da gestão da ética.

Os processos de mudança nas organizações refletem a necessidade de envolver a força de trabalho num novo padrão de comportamento organizacional com o objetivo de criar mais cooperação, participação e empreendedorismo compartilhado, sem uso de controle ou supervisão ostensiva. O planejamento de ações administrativas destinadas ao público interno, consubstanciadas em significados lógicos, emocionais e éticos, é a ferramenta mais adequada para promover essas mudanças. No entanto, alguns erros são comuns nesse processo, como a falta de sentido de urgência, o não envolvimento da alta direção e a ausência de uma equipe apoiada por ela para comandar a mudança. Também são erros comuns subestimar o poder da visão corporativa; não transmitir a visão de mudança; não fomentar o empowerment ("empoderamento"); não obter resultados em curto prazo; satisfazer-se com resultados imediatos sem consolidá-los para criar mais mudanças; não incorporar as mudanças à cultura da empresa (KOTLER, 1997 apud Torres Junior, 2002).

Sarmento, Freitas e Vieira (2008) consideram que elaborar, formalizar e impor o Código de Ética sem ações específicas de promoção, avaliação e reformulação podem levá-lo ao esquecimento no curto prazo, com o risco de transformar-se em fonte de ressentimentos entre os membros da organização. E as violações ao Código de Ética, tanto por parte de níveis hierárquicos superiores quanto inferiores, sem a oportuna reação da empresa, causam a perda de credibilidade dos programas de gestão da ética e inviabilizam a aplicação do código. Para os autores, a capacidade de influenciar o comportamento de agentes cuja conduta se pretende orientar depende de dezesseis variáveis que se relacionam com a forma de elaboração do código e o processo de gestão dele na empresa:

- justificação

- exemplificação

- linguagem

- extensão

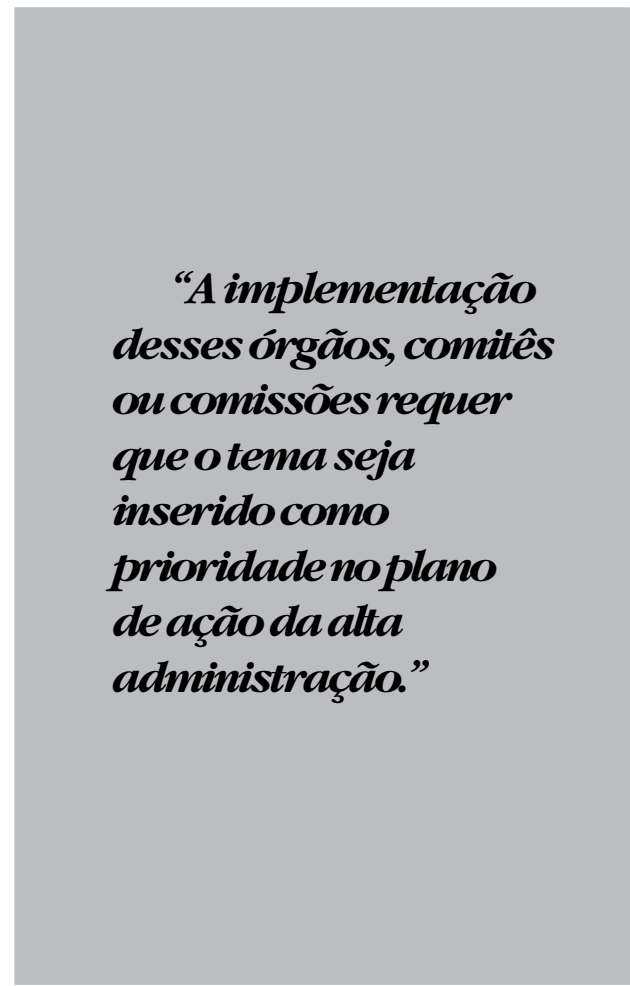

- participação na elaboração

- assinatura do código

- treinamento

- reforço

- prática efetiva pela empresa

- obrigatoriedade de comunicação de desvios

- divulgação de violações

- sistema de punições e recompensas

- exigência de cumprimento 
- linha telefônica anônima

- Comitê de ética

- Auditoria de ética

Para os autores, a conformidade e o envolvimento constituem fatores que influenciam a efetividade dos programas de gestão da ética.

Estudo de dois casos: sucesso e fracasso no processo de implementação das Comissões de Etica Setoriais

\section{Método}

Como implementar Comissões de Ética Setoriais? Há lacunas no processo de implementação das Comissões? Quais seriam os meios para transpor as dificuldades inerentes a esse processo? Neste trabalho, as questões suscitadas sugerem abordagens metodológicas variadas, mas mantém-se o eixo qualitativo. Essas perguntas direcionaram o desenvolvimento de pesquisa indutiva, exploratória e qualitativa (YIN, 2003), sendo dois casos estudados: um de sucesso e outro de fracasso no processo de implementação de Comissões de Ética Setoriais em dois órgãos do Poder Executivo Federal. Considerou-se caso de sucesso a Comissão que cumpre com todas as atribuições previstas na legislação: orienta; aconselha; promove a disseminação, capacitação e treinamento sobre as normas éticas; apura denúncias; supervisiona a observância do Código; elabora e executa um plano de trabalho; mantém uma secretaria-executiva - ou seja, não se restringe a ter apenas os membros nomeados em cumprimento à legislação. O caso de fracasso representa os órgãos que se restringem a cumprir a lei: têm os membros da Comissão nomeados para responderem às demandas legais e aos compromissos com a Comissão de Ética
Pública da Presidência da República, mas não executam em plenitude as atribuições.

A seleção dos casos é resultado da observação dos depoimentos dos membros dessas Comissões, em workshop do Curso de Gestão da Ética Pública, ministrado pela CEP/PR em junho de 2008. Na ocasião, identificou-se que os dois órgãos se encontravam em diferentes níveis no processo de implementação das Comissões de Ética Setoriais.

O caso identificado como de fracasso possui uma Comissão de Ética nomeada, mas que não realiza as atribuições de promoção, acompanhamento e fiscalização do programa de gestão da ética na instituição. O caso de sucesso caracteriza-se por ter uma Comissão de Ética Setorial atuante desde 2004. A Comissão está em pleno exercício das atribuições legais, pedagógicas e de avaliação e controle da ética.

Foram entrevistados três servidores públicos, entrevistados-chave, membros das Comissões de Ética Setoriais desses órgãos. O roteiro da entrevista qualitativa do tipo semiestruturada foi organizado em tópicos: dados da instituição, informações profissionais, interesse e importância do trabalho da Comissão de Ética Setorial, histórico da CES, realizações da CES, estrutura física e organizacional da CES, dificuldades para colocar em prática a CES. O propósito foi identificar os instrumentos e entraves para a implementação da Comissão de Ética Setorial. As entrevistas foram gravadas e as transcrições delas foram enviadas aos entrevistados para validação. O estudo não se restringiu à análise de dados primários: dados secundários como decretos, portarias, código e apostilas também foram utilizados.

As entrevistas e demais dados foram codificados e analisados segundo o 
estabelecimento de duas categorias: Instrumentos de implementação da Comissão de Ética Setorial e Dificuldades para execução. Cada categoria gerou subcategorias indicadas pela literatura e emergentes do processo de análise. Foram elaboradas fichas-síntese para cada caso estudado e tabelas analíticas dos dados coletados, utilizadas no estudo comparativo entre os dois casos.

Os quadros analíticos foram construídos a partir da ficha-síntese de cada caso e representam as categorias emergentes de instrumentos de implantação da Comissão de Ética Setorial com as respectivas dificuldades de implementação. A categoria Instrumentos de implementação da Comissão de Ética Setorial subdivide-se em três grupos:

1) Instrumentos normativos;

2) Instrumentos pedagógicos

3) Instrumentos estruturais, os quais foram divididos a partir da literatura e da identificação de ocorrências durante o processo de análise.

Essas subcategorias indicam a aplicação das normas vigentes, a utilização de instrumentos pedagógicos para divulgação da ética e as condições estruturais para a implementação da Comissão, como local, orçamento, criação de Secretaria Executiva e orientação da Comissão de Ética Pública da Presidência da República. A categoria Dificuldades para a implantação da Comissão compõe-se de dez itens que constituem obstáculos encontrados na literatura e explicitados pelos entrevistados no processo de implementação da Comissão de Ética Setorial, quais sejam:

- perfil adequado dos membros que constituem a Comissão;

- mudança constante dos membros da Comissão e das pessoas que atuam para disseminar o tema nos órgãos;
- grau de comprometimento da alta administração;

- resistência da alta administração;

- estrutura organizacional do órgão;

- tempo exíguo para realizar os trabalhos da Comissão em função do acúmulo de funções dos servidores;

- local exclusivo para o estabelecimento da Comissão;

- disponibilidade de orçamento para compra de material para divulgação e contratação de palestrantes;

- criação da Secretaria Executiva;

- perfil adequado dos membros da Secretaria Executiva.

Os instrumentos normativos constituem o arcabouço legal de princípios de conduta ética para o servidor público e são fundamentais para o processo de gestão da ética. Leis, decretos e regulamentos devem determinar os valores que devem reger o serviço público e prover as ferramentas de orientação, investigação, ação disciplinar e denúncia, segundo a Organização para a Cooperação e Desenvolvimento Econômico (OCDE, 1998).

A primeira ação para instituir e implantar o Programa de Gestão da Ética foi aprovar o Código de Ética Profissional do Servidor Público Civil do Poder Executivo Federal, em 1994. Em 1999, cria-se a Comissão de Ética Pública. Em 2001, altera-se o Decreto de 1999 para dar providências sobre o relacionamento das comissões de ética de órgãos e entidades da Administração Federal com a CEP. Em 2002, é instituído o Código de Conduta Ética dos Agentes Públicos em exercício na Presidência e Vice-Presidência da República. Regulamenta-se o impedimento de autoridades exercerem atividades ou prestarem serviços após a exoneração do cargo que ocupavam e a remuneração compensatória a elas devida pela União; 
além disso, são disciplinadas as audiências concedidas a particulares por agentes públicos em exercício na administração pública federal, nas autarquias e fundações públicas federais. Em 2007, institui-se o Sistema de Gestão da Ética do Poder Executivo Federal. Além da legislação específica, o assunto também é abordado na Constituição Federal, art.37; na Lei 8.112/90, Título IV; na Lei 8.429/92; na Consolidação das Leis do Trabalho (CLT), arts. 482, 483, 493 a 495 e 499; no Código Penal, Título X e na Lei 9.784/99, constituindo normatização complementar à matéria.

No início dos anos 2000, em meio ao processo de reestruturação do Estado, o Brasil ratifica três Convenções Internacionais contra a corrupção, no âmbito dos foros multilaterais. Em 2000, promulga a Convenção sobre o combate da corrupção de funcionários públicos estrangeiros em transações comerciais internacionais da OCDE; em 2002, a Convenção Interamericana contra a Corrupção, da Organização dos Estados Americanos (OEA); em 2006, a Convenção das Nações Unidas contra a Corrupção, da Organização das Nações Unidas (ONU). O compromisso assumido em âmbito internacional cria maior comprometimento do Estado com o desenvolvimento do Sistema de Gestão da Ética, uma vez que o país passa a ser observado pelas efetivas ações adotadas contra a corrupção e o Sistema constitui o instrumento de resposta efetiva para as recomendações desses organismos.

Os instrumentos pedagógicos, meios pelos quais se assegura a adaptação recíproca do conteúdo informativo aos indivíduos que se deseja formar (Houaiss, 2004), associados a ferramentas de marketing, são utilizados para difundir e disseminar os padrões de conduta ética. Relatórios da OCDE, publicados a partir de 1997 com dados de nove países Inglaterra, Noruega, Países Baixos, Finlândia, Estados Unidos, Austrália, Nova Zelândia, México e Portugal indicam que nem a legislação, nem os procedimentos administrativos e tampouco os padrões de conduta são de pleno conhecimento do servidor público. Essa constatação revela a necessidade do desenvolvimento de ações pedagógicas para a disseminação e difusão das normas éticas entre os agentes públicos. A socialização profissional constitui uma das ferramentas indicadas pela OCDE para a promoção da ética no serviço público. Essa socialização profissional se dá por meio de educação e treinamento (CARneiro, 1998).

Nas organizações, a dimensão pedagógica dos programas de ética estabelecese por meio de atividades gerenciais nas áreas de treinamento e comunicação. Código de ética ou de conduta; cópias das políticas da empresa; artigos de ética e newsletter da empresa; treinamento face a face, conduzido pelo pessoal de treinamento interno, pela gerência e por consultores externos; mensagens dos Senior Managers; programas de ética em vídeo; brochuras sobre questões específicas; treinamento “web based" são mecanismos que instrumentalizam o treinamento e promovem a ética nas instituições (MEIRA, 2005).

A utilização de um mix de marketing - contato pessoal, propaganda, publicidade e relações públicas, materiais de instrução - tem o objetivo de desenvolver a conscientização, informar, persuadir e relembrar as pessoas sobre o assunto proposto. O objetivo de promover um programa de comunicação da ética pode 
ser alcançado com a utilização dos recursos de comunicação que mais se adaptem ao perfil dos funcionários: folhetos, cartazes, artigos em publicações da empresa, vídeos, concursos. Esses instrumentos servem para estimular o interesse positivo por um determinado tema (LOVELOCK e WirTZ, 2006; SARMENTO, Freitas e Vieira, 2008).

O processo de capacitação para a ética pressupõe que os gestores associem a revisão do sucesso ou fracasso das iniciativas pedagógicas com o monitoramento dos canais de comunicação, a fim de construírem curvas de aprendizado para essas atividades. E que eles verifiquem, de forma sistemática, o impacto da atividade sobre o comportamento dos empregados, para atualizar os programas de treinamento e as iniciativas de comunicação. À medida que esses instrumentos são utilizados, o conceito de ética tende a se sedimentar (MeIra, 2005).

Os instrumentos estruturais relacionam-se com a dimensão física e estratégica para a consecução das atribuições das Comissões de Ética Setoriais. Constituem, portanto, os recursos materiais, operacionais e técnicos que viabilizam pôr em execução as atividades das Comissões. O Decreto n⿳o 6.029 de 2007 prevê a instalação de uma Secretaria Executiva, vinculada administrativamente à instância máxima do órgão público do Poder Executivo Federal, para executar o Plano de Trabalho da Comissão de Ética Setorial. Como instância executiva, a Secretaria requer local exclusivo para realização diária dos trabalhos, material disponível e pessoas capacitadas para proverem o apoio técnico necessário ao cumprimento das atribuições da Comissão.

No âmbito estratégico, o Plano Plurianual (PPA) 2008-2011 estabelece as diretrizes do Programa de Gestão da Ética. O Plano prevê a CEP como executora das ações do Programa 1143, que estabelece a promoção da ética pública, disseminação do Código de Conduta Ética no serviço público federal e capacitação de servidores e agentes públicos quanto à ética pública, bem como gestão e administração do Programa. Para a consecução dessas atribuições, a Comissão apresentou os

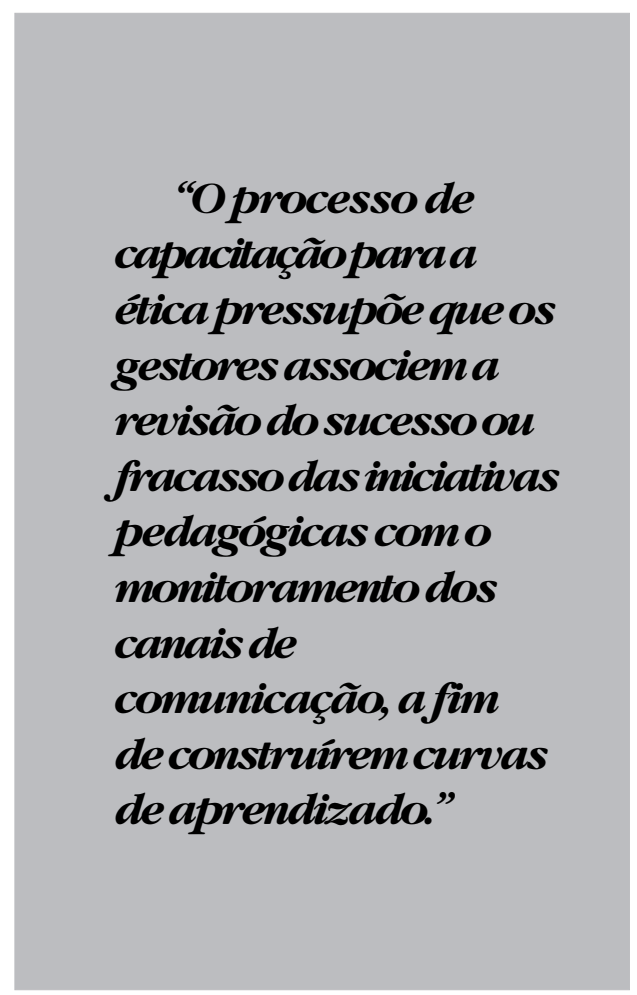

seguintes projetos para 2008: realização de cursos e seminário; desenvolvimento de pesquisa sobre valores éticos e promoção de avaliação dos órgãos e entidades sobre a gestão da ética. Esses projetos visam orientar e capacitar as Comissões de Ética Setoriais e constituem instrumentos essenciais ao desenvolvimento do Programa de Gestão da Ética no Serviço Público Federal. 


\section{Resultados}

Os resultados da análise dos dados coletados nas entrevistas evidenciam que os dois casos estudados se encontram em estágios diferentes de implantação da Comissão de Ética Setorial.

\section{Caso sem êxito: entidade A}

Os dados coletados nas entrevistas com os membros da Comissão de Ética Setorial do caso em que não houve êxito evidenciam que o processo de implementação da Comissão está em fase incipiente. A Comissão foi nomeada em 2007, mas não atua, nem executa nenhuma das competências a ela atribuídas pelo Decreto $\mathrm{n}^{\circ} \mathbf{0} .029$ de 2007. Sua atuação restringe-se à aplicação do Código de Conduta Ética Profissional do Servidor Público, de 1994, e às normas específicas para a condução da gestão da ética no serviço público federal.

$\mathrm{Na}$ categoria Instrumentos de implementação, não há registro de aplicação para quase todos os tipos de instrumentos analisados. Não disponibiliza textos doutrinários, mensagens ou filmes; não promove palestras, cursos ou cafés da manhã; não faz avaliações; não capacita servidores para divulgar a ética; e apenas alguns membros da Comissão participaram do curso promovido pela Comissão de Ética Pública da Presidência da República. A comissão limita-se a atender às convocações da CEP. A inutilização de ferramentas que promovam a educação e o treinamento para a ética dificulta tanto a socialização profissional quanto a promoção da ética no serviço público, que, para Carneiro (1998), dá-se por meio desses instrumentos.

$\mathrm{Na}$ categoria Dificuldades, todos os itens analisados foram considerados como entraves existentes para o processo de implantação da Comissão nesse primeiro caso analisado. Os membros em estágio probatório, ou em níveis hierárquicos inferiores, sentem muita dificuldade para a realização das atividades da Comissão, fator que consideram contribuir para o seu enfraquecimento. Constantes mudanças dos membros impedem a execução de um plano de ação. Não há servidores capacitados para divulgar o tema e existe pouco comprometimento da alta administração. Verificamse evidências quanto à resistência em relação ao processo de apuração de denúncias. A estrutura organizacional muito pequena e inadequada para a realização das atividadesfim impede a implementação da Comissão, uma vez que o acúmulo de tarefas e funções, assim como o déficit de pessoal, restringe o tempo disponível para a realização das atividades. Além disso, não há local exclusivo nem disponibilidade de salas para reuniões reservadas, tampouco orçamento disponível para compra de material de divulgação. A Secretaria Executiva ainda não foi instituída e verifica-se a dificuldade em encontrar a pessoa adequada, com disponibilidade para assumi-la.

As dificuldades apontadas pelos entrevistados reforçam as considerações de Daft (2006) sobre a eficácia das ferramentas para a configuração dos valores éticos em organizações que pressupõem uma liderança baseada em valores e adequação da estrutura e sistemas organizacionais. Sem a liderança dos níveis hierárquicos superiores responsáveis pela criação e manutenção de uma cultura que enfatize a importância da conduta ética para todos os funcionários, será difícil, para o autor, desenvolver e executar um padrão ético.

Os resultados deste caso confirmam a complexidade no processo de implantação de política pública de enfoque top down. Caso os executores da política não 
sejam eficazes, haverá um hiato de implementação e a política não será colocada em prática de forma apropriada (OEI, 2002). O sentimento de fragilidade e falta de autonomia dos membros dessa Comissão de Ética Setorial, bem como o excesso de atribuições dos servidores e o déficit de pessoal, impedem que as ações sejam efetivadas. Além disso, duas das dificuldades identificadas por Kotler (1997 apud TORRES JUNIOR, 2002) aparecem como fatores impeditivos do desenvolvimento pleno das atividades da comissão: a falta de comprometimento da alta direção e a ausência de uma equipe apoiada por ela para comandar o processo de implantação da comissão e do Programa de Gestão da Ética.

\section{Caso de sucesso: entidade B}

A entrevista com o presidente da Comissão de Ética Setorial do caso considerado como de sucesso confirmou a percepção, detectada no workshop do Curso de Gestão da Ética Pública, de que o órgão se encontra em fase avançada de implementação de sua Comissão de Ética Setorial. A CES do órgão foi nomeada em 2004 e atua de forma efetiva desde a sua criação: aplica e divulga o Código de Ética específico do órgão, apura denúncias e realiza trabalho pedagógico e de orientação; além disso, está em processo de criação da Secretaria Executiva.

Os resultados obtidos com a análise dos dados deste caso evidenciam que o órgão tem uma Comissão de Ética Setorial em pleno exercício das funções. E confirmam as propostas de Queiroz, Dias e Prado (2008), em que a Comissão tem como atribuições atualizar o Código de Ética; promover treinamento dos empregados para disseminar a cultura ética na organização; e implementar um sistema de monitoramento do programa. Explicitam, ainda, o seguimento das normas previstas (BRASIL, 2007).

Os dados são inversos aos do caso anteriormente apresentado. Ao contrário da outra comissão, a maior parte dos tipos de instrumentos analisados é aplicada. O Código de Ética específico foi elaborado e aprovado em 2003 e, imediatamente, distribuído a todos os servidores e colaboradores. Textos doutrinários de autores diversos são distribuídos periodicamente aos "Embaixadores da Ética" - pessoas comprometidas em promover e disseminar a ética - e aos superintendentes por meio da intranet; o "Momento Ético" é uma mensagem diária enviada aos servidores por meio da intranet. Filmes são apresentados para depois serem debatidos. Palestras, cursos e cafés da manhã também são promovidos. Foi instituído o "Módulo de Ética" em todos os cursos de capacitação dos servidores e as avaliações para mensurar o grau de receptividade do tema são realizadas por meio da aplicação de questionários. Todos os membros da Comissão, os superintendentes, os representantes de cada gerência e das regionais são capacitados e denominados "Embaixadores da Ética”, e participam do Curso de Gestão da Ética Pública da CEP. Para esses membros, a Comissão de Ética Pública estimula e norteia as ações da CES que, sempre que necessário, recorre à CEP para buscar orientação. Apesar de não possuir local exclusivo para os trabalhos $\mathrm{da}$ Comissão, há muita disponibilidade para reservar local para as reuniões. O orçamento da Comissão é vinculado ao da presidência e suficiente para atender às necessidades de realização das atividades. A Comissão realizou, até o final de 2008, 32 reuniões para deliberar sobre a ética.

Apenas quatro itens foram considerados como dificuldades para a implementação 
desta Comissão. Seus membros pertencem a níveis hierárquicos superiores, assessores de diretoria e superintendentes, sendo obrigatória a presença do superintendente de recursos humanos. Fator que torna a Comissão forte, para Willey (1997), isso representa o reconhecimento da existência de dilemas morais pela direção, cujos esforços concentram-se em que sejam tomadas as decisões certas. Há constantes mudanças das pessoas capacitadas para divulgar o tema. A alta administração é muito comprometida, consciente e não oferece resistência. A estrutura organizacional adequada facilita os trabalhos da comissão. Entretanto, o pouco tempo disponível para dedicação exclusiva aos trabalhos da Comissão limita as novas ações e desenvolvimento de instrumentos pedagógicos. A Secretaria Executiva não tinha sido instituída até o final de 2008, mas constitui a maior prioridade da Comissão. A maior dificuldade está em encontrar a pessoa adequada com disponibilidade para assumi-la.

A análise dos resultados indica que a entidade $\mathrm{B}$ desenvolve o trabalho de gestão da ética por meio da implementação de sua CES. Para o presidente da Comissão de Ética Setorial, "em matéria de estrutura da ética, nós estamos bem. Só não conseguimos implementar do jeito que a gente gostaria de implementar. Porque o tema precisa de atenção e encaminhamento. É um processo mais de conquista”. Há a percepção de que, apesar da utilização de diversos instrumentos pedagógicos para a divulgação da ética, e poucas dificuldades para a implantação, há muito a ser feito. A experiência de sucesso, nesse processo, indica caminhos a serem seguidos. E pode ser entendida como resposta à experiência em que não houve êxito.

A experiência de sucesso confirma as percepções de Carneiro (1998) e Daft
(2006) de que a existência de normas por si só é insuficiente para a realização do trabalho de orientação para a conduta ética; faz-se necessária a inserção do tema como prioridade da alta administração. $\mathrm{O}$ apoio da alta administração do órgão à Comissão, segundo o entrevistado, foi preponderante para o desenvolvimento dos trabalhos e envolvimento de todos os níveis hierárquicos no processo. Além disso, denotou predisposição da alta administração para o debate do tema no órgão e indicou, ainda, a importância do assunto, gerando credibilidade nas ações propostas.

Os instrumentos pedagógicos utilizados pela Comissão de Ética Setorial do caso de sucesso constituem um banco de idéias que se formou com a coleta de sugestões para implementar um plano de ação. Para trabalhar com a gestão da ética, foram indicadas 106 pessoas, que coletaram mais de 70 idéias para atuação no campo preventivo. Tais idéias podem ser categorizadas entre o mix de comunicação utilizado para promover treinamento em ações pedagógicas sobre ética (Sarmento, Freitas e Vieira, 2008; Meira, 2005). De forma gradativa e diversificada, as idéias são implementadas com o objetivo de não cansar o servidor. Assim o tema se faz sempre presente no cotidiano do órgão. $\mathrm{O}$ trabalho constante em campanhas preventivas e de conscientização tem diminuído as denúncias e propiciado a criação de um ambiente organizacional agradável.

Sugestão de ações que podem favorecer a efetiva implantação das CES e meios para transpor as dificuldades inerentes ao processo

O estudo sugere ações para a implementação eficiente de Comissões de Ética Setoriais no serviço público. Um processo 
eficaz inicia-se com a nomeação de uma Comissão vinculada à alta administração do órgão e com poder de influenciar as decisões para a elaboração de um plano de ação. Os membros da Comissão devem estimular a participação de servidores identificados como sensíveis ao tema para serem divulgadores da ética e interlocutores dos servidores junto à Comissão. A alta administração deve estar comprometida e consciente sobre a importância do tema, estimulando a participação de todos no transcorrer desse processo.

Daft (2006) preconiza que o Código de Ética constitui importante ferramenta para o gerenciamento dos valores organizacionais; a elaboração do Código de Ética Específico é, assim, ação primordial para iniciar o processo de divulgação. É por meio dele que as normas de conduta do órgão ficam estabelecidas e minimizam-se os sentimentos de falta de credibilidade para apuração de denúncias.

A Comissão fortalecida, com membros da alta administração e com uma rede de colaboradores nos departamentos e nas gerências do órgão, deve atuar como coordenadora do plano de ação para executar os instrumentos pedagógicos de divulgação da ética. Os trabalhos no âmbito preventivo devem incluir o estímulo a novas idéias e a seleção delas para aplicação gradual e contínua. A instituição de uma Secretaria Executiva, tal qual prevê o Decreto 6.029 de 2007, é fundamental para a execução das ações propostas. Nesse aspecto é necessário prever, na estrutura organizacional e nas dependências do órgão, local adequado para a instalação da Secretaria Executiva e disponibilizar salas de reunião privativas para o atendimento particular e apuração de denúncias. Atendem-se, assim, os pressupostos de Daft (2006) para configuração da ética, em que se prevê uma liderança baseada em valores e a criação de estruturas e sistemas organizacionais que favoreçam a ética gerencial.

A avaliação das ações colocadas em prática deve ser constante. Questionários de avaliação quanto à sensibilidade dos servidores ao tema são importantes no início do processo de implementação para direcionar os trabalhos da Comissão. Esse questionário preliminar auxilia na tomada de decisões no que se refere à ênfase dada a cada ação. A rede de colaboradores da Comissão deve atuar para coletar sugestões e identificar a percepção dos servidores quanto às ações adotadas na condução do tema.

As atividades de promoção e divulgação da ética podem ser feitas por meio de mensagens eletrônicas veiculadas na intranet, textos doutrinários de filósofos e especialistas no tema, filmes, cursos, palestras, cartazes, banners, encontros com projeção de mensagem sobre ética e capacitação. $\mathrm{O}$ instrumento mais eficiente para a divulgação do tema é a inserção de um módulo sobre ética nos cursos de capacitação dos servidores, seja no ingresso à instituição ou em cursos de atualização. Assim, a diretoria de recursos humanos deve estar envolvida e comprometida com o processo de implementação da Comissão de Ética Setorial.

As sugestões propostas visam minimizar as dificuldades encontradas no processo de implementação de Comissões de Ética Setoriais no serviço público federal. O estudo dos dois casos apresentados denota que a adoção ou não dessas medidas influencia no processo de implementação da Comissão e determina o curso das ações no âmbito da política pública de gestão da ética. Dessa forma, uma rede integrada de mecanismos é essencial para o sucesso da implementação de um sistema de gestão da ética, pois o 
processo de prevenção de transgressões éticas é tão complexo quanto o fenômeno de transgressão em si (OCDE, 1998).

\section{Conclusão}

O estudo dos dois casos de implantação de Comissões de Ética Setoriais, um identificado como de sucesso e outro em que não houve êxito, ajudou a responder a questão proposta de como colocar em prática Comissões de Ética Setoriais. $O$ estudo indica que as dificuldades encontradas no caso de fracasso são solucionadas com a implementação das políticas adotadas pelo caso de sucesso. E evidencia que a adoção sistemática de instrumentos pedagógicos para a promoção da ética, o comprometimento da alta administração do órgão e a criação de uma rede interna de pessoas capacitadas e sensíveis ao tema possibilitaram a implantação eficiente da Comissão de Ética Setorial na entidade B.

As dificuldades para a implementação das Comissões de Ética Setoriais relacionam-se mais com os aspectos políticos de comprometimento da alta administração do órgão que com os aspectos instrumentais dessa. Uma vez que os instrumentos normativos estão determinados pela legislação e tanto os instrumentos pedagógicos quanto os estruturais constituem ações gerenciais, para executar as ações do Sistema de Gestão da Ética é necessário que os gestores públicos demonstrem comprometimento com o tema e percebam a importância de apoiar os membros da Comissão de Ética Setorial na execução das atribuições.

O Sistema de Gestão da Ética, por constituir um modelo de cima para baixo de implementação de políticas públicas, exige o esforço dos executores para envolverem e sensibilizarem todos os níveis hierárquicos num processo contínuo de aprendizagem e avaliação. Assim, a adoção de medidas pontuais como a nomeação de membros para as Comissões, que tenham grande poder de decisão, aumenta a probabilidade de a implementação dessas comissões ocorrer de forma mais eficiente.

Apesar de a ética estar na pauta da administração pública federal, no âmbito do Poder Executivo Federal, desde 1994, há poucos estudos sobre o processo de implementação das Comissões de Ética Setoriais. O número restrito de publicações específicas sobre comitês de ética indica que há muito a ser feito nessa área.

(Artigo recebido em julho de 2009. Versão final em março de 2010)

\section{Referências bibliográficas}

Arruda, M.C.C. A ética no marketing das indústrias de bens de consumo no Brasil. RAE - Revista de Administração de Empresas. São Paulo: EASP/FGV, v. 33, n.1, p. 16-28, jan./fev. 1993.

Amorim, S. N. D. Ética na esfera pública: a busca de novas relações Estado/sociedade. Revista do Serviço Público. Brasília: Fundação Escola Nacional de Administração Pública (ENAP), v.51, n.2, p. 94-104, abr./jun. 2000.

Bauman, Z. Ética pós-moderna. Trad. João Rezende Costa. São Paulo: Paulus, 1997. 
Brasil. Presidência da República, Casa Civil, Comissão de Ética Pública. Desvios Éticos: risco institucional. Brasília: ESAF, 2002.

. Decreto n. 6.029, de 1ำ de fevereiro de 2007. Institui Sistema de Gestão da Ética do Poder Executivo Federal, e dá outras providências. Lex: Código de Conduta da Alta Administração Federal, Brasília, 3ae ed., 2007. Presidência da República, Comissão de Ética Pública.

. Decreto n⿳⺈ 1.171, de 22 de junho de 1994. Aprova o Código de Conduta Ética Profissional do Servidor Público. Lex: Código de Conduta da Alta Administração Federal, Brasília, 3 ed., 2007. Presidência da República, Comissão de Ética Pública.

Carneiro, J.G.P. O aprimoramento da conduta ética no serviço público federal. Revista do Serviço Público. Brasília: Fundação Escola Nacional de Administração Pública (ENAP), v. 49, n.3, p. 120-133, jul./set. 1998.

Chanlat, J.F. A caminho de uma nova ética das relações nas organizações. Tradução de Maria Irene Stocco Betiol. (RAE) Revista de Administração de Empresas. São Paulo: EASP/ FGV, v.32, n.3, p. 68-73, jul./ago. 1992.

Clegg, S.; Carter, C.; Kornberger, M. A Máquina Estratégica: Fundamentos Epistemológicos e Desenvolvimentos em Curso. (RAE) Revista de Administração de Empresas. São Paulo: EASP/FGV, v.44, n.4, out./dez. 2004.

DAfT, R. L. Organizações. Teorias e Projetos. Tradução: Cid Knipel Moreira. São Paulo: Thomson Learning, 2006. pp. 291-318.

DaMAtTA, R. Considerações sócio-antropológicas sobre a ética na sociedade brasileira. Informe de Consultoria apresentado ao Banco Interamericano de Desenvolvimento, 20 nov. 2001.

Frey, K. Políticas Públicas: um debate conceitual e reflexões referentes à prática da análise de políticas públicas no Brasil. Planejamento e Políticas Públicas, v. 21, jun. 2000.

LAMEIRA, V. J.; BERTRAND, H. Ethics, corruption, governance and emergingmarkets. REAd, v.14, n.1, ed. 59, 2008.

LOVELOCK, C.; WIRTZ, J. Marketing de serviços: pessoas, tecnologias e resultados. Tradução: Arlete Simille Marques. São Paulo: Pearson Prentice Hall. p. 105-127, 2006.

Machado Filho, C.A.P.; ZylberszTajn, D. A empresa socialmente responsável: o debate e as implicações. Revista de Administração, v. 39, nº 3, p. 242-254, 2004.

Matias-pereira, J. Manual de gestão pública contemporânea. São Paulo: Atlas. p. 45-54, 2008.

MeirA, F. B. O processo de burocratização da ética ou como se produz a ética na própria empresa. In: XXIX EnANPAD - Encontro da ANPAD, 2005, Brasília.

Miles, M. B.; Huberman, A. M. Qualitative data analysis: an expanded Sourcebook. 2. ed. Thousand Oaks, CA: Sage, 1994.

Organização para Cooperação e Desenvolvimento Econômico (OCDE). Principles for managing ethics in the public service. OECD Recommendation, 1998.

Organização dos Estados Ibero-Americanos (OEI). Metodologia de Análise de Políticas

Públicas. São Paulo: GAPI - UNICAMP, 2002. 
Queiroz, H.M.G.; Dias, A R.; Prado, T. L. Código de ética: um instrumento que adiciona valorestudo comparado em três instituições bancárias. In: XXXII EnANPAD Encontro da ANPAD, 2008, Rio de Janeiro.

Sarmento, A.C.C.; Freitas, J.A.S.B.; Vieira, P.R.C. Códigos de ética empresarial: uma análise de fatores que influenciam sua efetividade. In: XXXII EnANPAD Encontro da ANPAD, 2008, Rio de Janeiro.

Seminário Internacional De Ética Como Instrumento De Gestão. III Encontro de Representantes Setoriais da Comissão de Ética Pública. Brasília: ESAF, 2002.

TORRes Junior, A.S. Retórica organizacional: lógica, emoção e ética no processo de gestão. ERA eletrônica, v. 1, n.1, 2002.

Yin, R. K. Estudo de caso: planejamento e métodos. 2ª ed. Porto Alegre: Bookman, 2003.

WELLS, B.; SPINKS, N. Ética, de cima para baixo. Career Development International, HSMManagement, n. 7, mar./abr. 1998. Disponível em: <http://www.hsm.com.br/hsmmanagement/edicoes/ numero_7/etica_cima_para.php $>$. Acesso em: 30 setembro, 2008.

Wells, C. O ABC da Ética. HSM Management. mar./abr. 1997. Disponível em: $<$ http://www.perspectivas.com.br/refle33.htm>. Acesso em: 30 setembro, 2008. 


\section{Resumo - Resumen - Abstract}

\section{Comissão de Ética Setorial: os desafios de fazer cumprir a ética na administração públi- ca federal}

Annita Valléria Calmon Mendes, Hermes de Andrade Júnior, Rodolfo Pinto da Lu₹ e Cândido-Borges

Este texto parte do reconhecimento de que a implementação de Comissões de Ética Setoriais constitui componente fundamental para concretizar a promoção da ética no âmbito do Sistema de Gestão da Ética do Poder Executivo Federal. Entretanto, essa não é uma tarefa simples. A análise de dados secundários e a revisão da literatura sobre o tema suscitam as questões: como implementar Comissões de Ética Setoriais? Há lacunas no processo de implantação? Quais seriam os meios para transpor as dificuldades inerentes a esse processo? Realizou-se pesquisa exploratória, indutiva, qualitativa. O estudo de dois casos (um de sucesso e outro de fracasso no processo de implementação dessas Comissões) indica que a adoção sistemática de instrumentos pedagógicos para a promoção da ética, o comprometimento da alta administração e a criação de uma rede interna de pessoas capacitadas e sensíveis ao tema são elementos importantes nesse processo. O estudo sugere, ainda, ações que podem favorecer a efetiva implementação dessas Comissões.

Palavras-chave: Comissão de ética setorial; ética; Poder Executivo Federal

\section{Comisión de ética sectorial: los desafíos de hacer cumplir la ética en la administración pública federal}

Annita Valléria Calmon Mendes, Hermes de Andrade Júnior, Rodolfo Pinto da Luz e Cândido Borges

Este texto parte del reconocimiento de que la implementación de Comisiones de Ética Sectoriales constituye componente fundamental para materializar la promoción de la ética en el Sistema de Gestión de la Ética en el Ejecutivo Federal. Sin embargo, esta no es una tarea simple. El análisis de datos secundarios y la revisión de la literatura sobre el tema suscitan las cuestiones: ¿Cómo implementar Comisiones de Ética Sectoriales? ¿Hay lagunas en el proceso de implantación de las Comisiones? ¿Cuáles serían los medios para superar las dificultades inherentes a este proceso? Se realizó investigación exploratória, inductiva y cualitativa. El estudio de dos casos (uno de éxito y el otro de fracaso en el proceso de implementación de estas Comisiones) indican que la adopción sistemática de los instrumentos pedagógicos para la promoción de la ética, el comprometimiento de la alta administración y la creación de una red interna de personas capacitadas y sensibles al tema son elementos importantes en este proceso. El estudio sugiere, aún, acciones que pueden favorecer la efectiva implementación de estas Comisiones.

Palabras clave: Comisión de Ética Sectorial; ética; Poder Ejecutivo Federal

Sectorial Ethics Commission: the challenges to make ethics happen at the federal public administration

Annita Valléria Calmon Mendes, Hermes de Andrade Júnior, Rodolfo Pinto da Luz e Cândido Borges

This paper acknowledges that implementation of Sectorial Ethics Commission constitutes a basic component to promote ethics on System of Management of the Ethics of the Federal Executive. This is, however, not a simple task. The analysis of secondary data and the revision of literature on the subject excite the questions: how to implement Sectorial Commissions of Ethics? Are there gaps in the process of implementation of the Commissions? Which would be the means to transpose the inherent difficulties to this process? An Exploratory, inductive, and qualifying research was held. The study of two cases: one successful and another failed in implementing these 
Commissions, both indicating that the systematic adoption of pedagogical instruments for the promotion of ethics, high administration commitment and the creation of an internal net of people able and sensible to the subject are important elements in this process. The study also suggests actions that can favor the effective implementation of these Commissions.

Keywords: Sectorial Ethics Commission; ethics; Executive Federal Administration

Annita Valléria Calmon Mendes

Mestranda em Administração UNIEURO, é especialista em Relações Internacionais, servidora pública federal e administradora do Instituto de Pesquisa de Relações Internacionais da Fundação Alexandre de Gusmão. Contato: annitacalmon@gmail.com

Hermes de Andrade Júnior

Doutor em Saúde Pública, é professor do Centro Universitário Euro-Americano (Unieuro) de Brasília (DF). Contato: handradejunior@gmail.com

Rodolfo Pinto da Luz

Doutor em Engenharia de Produção, é professor do Centro Universitário Euro-Americano (Unieuro) de Brasília (DF). Contato: 938@unieuro.edu.br

Cândido Borges

PhD em Administração e professor adjunto do Curso de Administração da Universidade Federal de Goiás. Contato: candidoborges@gmail.com 